\title{
A modified hydrodynamic model for routing unsteady flow in a river having piedmont zone
}

\author{
Sudarshan Patowary ${ }^{1 *}$, Arup Kumar Sarma ${ }^{2}$ \\ ${ }^{1}$ Dept. of Civil Engineering, Indian Institute of Technology, Guwahati, India. \\ ${ }^{2}$ Dept. of Civil Engineering, Indian Institute of Technology, Guwahati, India. E-mail: aks@iitg.ernet.in \\ * Corresponding author. Tel.: 09706830528. E-mail: s.patowary@iitg.ernet.in
}

\begin{abstract}
Existence of piedmont zone in a river bed is a critical parameter from among numerous variations of topographical, geological and geographical conditions that can significantly influence the river flow scenario. Downstream flow situation assessed by routing of upstream hydrograph may yield higher flow depth if existence of such high infiltration zone is ignored and therefore it is a matter of concern for water resources planning and flood management. This work proposes a novel modified hydrodynamic model that has the potential to accurately determine the flow scenario in presence of piedmont zone. The model has been developed using unsteady free surface flow equations, coupled with Green-Ampt infiltration equation as governing equation. For solution of the governing equations Beam and Warming implicit finite difference scheme has been used. The proposed model was first validated from the field data of Trout Creek River showing excellent agreement. The validated model was then applied to a hypothetical river reach commensurate with the size of major tributaries of Brahmaputra Basin of India. Results indicated a 10\% and 14\% difference in the maximum value of discharge and depth hydrograph in presence and absence of piedmont zone respectively. Overall this model was successfully used to accurately predict the effect of piedmont zone on the unsteady flow in a river.
\end{abstract}

Keywords: Groundwater flow; Numerical modeling; Piedmont zone; Green-Ampt. Equation; Surface water equation.

\section{INTRODUCTION}

Interaction between surface and groundwater flow in a nonprismatic river have been a topic of interest among researchers since last three decades owing to its significance in flood forecasting, dam break analysis, and watershed modelling. Interaction between the surface and the ground water is a complex phenomenon the quantification of which needs several considerations such as variations of topographical, geological, and geographical conditions. Coupled model between surface and groundwater are linked via an exchange of flux between the two systems. Saint-Venant equation has thus far been promisingly used to model unsteady open channel flow in a river (Fang et al., 2008; Keskin and Agiralioglu, 1997; Mohammad et al., 2007; Zhang and Shen, 2007). However, except for a few simple cases Saint-Venant equation is not amenable to analytical solutions requiring numerical methods such as implicit and explicit finite difference schemes for its solution (Fennema and Chaudhry, 1986; Mousseau et al., 2002; Ramesh et al., 2000). Implicit finite difference schemes are advantageous over explicit finite difference scheme in terms of stability and time step i.e. with implicit finite difference schemes one can go for much larger time step than explicit finite difference schemes thus reducing overall solution time of the problem. Beam and Warming (1976) developed a non-iterative implicit scheme for solution of hyperbolic system of equation. Further this scheme has been widely used by different researchers (Kalita and Sarma, 2012; Kalita et al., 2014; Kassem and Chaudhry, 1998; Molls et al., 1995) for solution of different hydraulic problem. Besides unsteady flow, the interactions between surface and subsurface water flow have also been successfully modelled using the Saint-Venant equation (shallow water equation) as governing equation for surface water flow (Kong et al., 2010; Liang et al., 2007; Suils et al., 2010). Niswonger et al. in 2005 developed a one-dimensional unsteady stream flow model to calculate the seepage loss in mountain front stream using Saint-
Venant equation as the governing equation and infiltration as source term in the continuity and momentum equation. The model, however did not solve the surface water and infiltration equation simultaneously instead used VS2DH seepage loss with stream depth look-up table to calculate the infiltration rate in the stream flow model. VS2DH is a computer based program, where advection- dispersion equation for single phase liquid water is used to describe energy transport in variably saturated porous medium. Several researchers (Beven, 1984; Chou, 1978; Dagan and Bresler, 1983; Govindaraju et al., 1996; Lui et al., 2008; Ma et al., 2010; Mein and Larson, 1973; Kacimov et al., 2010; Selker et al., 1999; Voller, 2011) used Green-Ampt equation for solution of different infiltration problem. Akanbi and Katopodes (1990), Fiedler and Ramirez (2000), Bateman et al. (2010) developed numerical model to simulate flood wave propagation on a dry bed where surface water was simulated by Saint-Venant equation with inclusion of infiltration term as the source term in continuity and momentum equation and rate of infiltration was calculated by Kostiakov infiltration equation, Green-Ampt infiltration equation respectively. In all the models the surface water depth and the presence of piedmont zone was ignored which could be critical for the accurate determination of infiltration rates in rivers. To address this issue we have for the first time in our previous work (Patowary and Sarma, 2013) proposed a mathematical model to compute the infiltration through the piedmont zone where such surface water depth is considered. However the proposed model suffered from the limitation of using a constant suction head assumption for the calculations that could introduce significant errors as the suction head parameter in Green-Ampt model is a function of time, surface water depth, initial moisture content and soil type (Freyberg et al., 1980). The model also used explicit finite difference scheme for solution of governing equation which had limitation for time step. Furthermore, the results were not validated in the previous work to claim the accuracy of the model. To address the shortcomings of our previous model this paper 
thus presents a significantly improved numerical method using an advanced coupled model with modified governing equation to simulate unsteady free surface flow in a river considering infiltration occurring through a piedmont zone under varying water depth and suction head. An implicit finite difference scheme was used to solve the governing equation with reduced computational time. Further, the model data was satisfactorily validated with the field data showing the promise of our model.

\section{MATHEMATICAL FORMULATION}

The proposed model has two components: 1) 1-D unsteady flow model for free surface flow computation, 2) infiltration model for computing time dependent infiltration rate and total infiltration.

\section{One dimensional unsteady flow model}

Figure 1 shows a sectional view of a river reach containing a piedmont zone through which a significant amount of water infiltrates into the ground. Because of this, water level at the downstream may decrease noticeably and sometimes may even become zero. Depending on the direction of groundwater movement, water infiltrating through the piedmont zone may either reach mainstream at downstream or can move to a river of adjacent catchment. However contribution of water from ground to surface is neglected in this model.

In the above figure, $Q=$ discharge at upstream of the piedmont zone, $q$ = water infiltrated through the piedmont zone.

One-dimensional continuity equation and fully dynamic form of the momentum equation was used for modelling the unsteady free surface flow. To account for the loss due to infiltration, a source term was added to these equations (Strelkoff, 1970). For small value of bed slope and with the assumption of hydrostatic pressure distribution the conservation form of the governing equation in the matrix form can be written as;

$$
\mathbf{U}_{t}+\mathbf{E}_{x}+\mathbf{S}=0
$$

where

$$
\mathbf{U}=\left(\begin{array}{l}
A \\
V A
\end{array}\right) \mathbf{E}=\left(\begin{array}{l}
V A \\
V^{2} A+g A \bar{y}
\end{array}\right) \mathbf{S}=\left(\begin{array}{l}
q \\
-g A\left(S_{0}-S_{f}\right)-m_{l}
\end{array}\right)
$$

where $m_{l}=0.5 q V ; S_{f}=V^{2} n^{2} / R^{4 / 3}$

where $A$ is the cross sectional area of the river, $\bar{y}$ is the depth of centroid of flow area, $V$ is the velocity, $A \bar{y}$ is the moment of flow area about the free surface, $g$ is acceleration due to gravity, $S_{o}$ is bed slope, $S_{f}$ is friction slope, $R$ is the hydraulic radius, $n$ is the Manning's roughness coefficient, $q$ is the lateral outflow ( $q=f \times L$ where $f$ is the infiltration rate and $L$ is the distance between two grids) per unit length of the channel, $m_{l}$ momentum loss because of infiltration (dynamic contribution of lateral discharge).

\section{Green-Ampt infiltration model to calculate time dependent infiltration rate}

Green-Ampt equation has been used extensively by the researchers to calculate the infiltration in different fields. In the original Green-Ampt equation height of the water depth (ponding depth) is neglected considering the assumption that infiltration rate is more than rate of water supplied. But to calculate the infiltration rate in a river this assumption may not be valid. Again Freyberg et al. (1980) found that the effective suction head in Green-Ampt equation is a function of time, surface water depth, initial moisture content and soil type. Infiltration rate through the recharge zone is therefore, calculated by using the following equation,

$$
\begin{aligned}
& f=k_{0}\left[1+\frac{\left[h_{e}(t)+H(t)\right]\left[\theta_{s}-\theta_{o}\right]}{F}\right] \\
& h_{e}(t)=\frac{F^{*}\left(f^{*}-k_{0}\right)}{\left(\theta_{s}-\theta_{o}\right) k_{0}}-H(t)
\end{aligned}
$$

where $F$ is the cumulative infiltration, $H(t)$ is the water surface height which is a function of time, $h_{e}(t)$ is the time dependent effective suction head, $\theta_{s}, \theta_{o}$ are the saturated and initial soil moisture content, $k_{0}$ is the saturated hydraulic conductivity. The values of $F^{*}$ and $f^{*}$ used in the Eq. (5) are taken as the values of $F$ and $f$ obtained from the solution of the Richards equation (Reeder et al., 1980) as follows:

The vertical soil moisture flow can be described by following form of Richards equation

$c(\psi) \frac{\partial \psi}{\partial t}=\frac{\partial}{\partial z}\left[k(\psi)\left(\frac{\partial \psi}{\partial z}+1\right)\right]$

where $\psi$ is the soil water pressure potential, $c(\psi)=d \theta / d \psi$ is the specific moisture capacity, $\theta$ is moisture content, $k(\psi)$ is the hydraulic conductivity, $z$ is the vertical space coordinate, $t$ is the time. After calculating the value of $\psi$, the infiltration rates are determined by applying the Darcy equation to the top layer of the soil column as per following equation

$$
f^{*}=k_{s}\left(\left|\frac{\partial \psi}{\partial z}\right|+1\right)
$$

When a saturated zone is form below the ground surface Darcy's law may be expressed as

$$
f^{*}=k_{s}\left[\frac{H(t)}{Z(t)}+1\right]
$$

where $H(t)$ is the surface water depth and $Z(t)$ is the depth of the saturated zone, $k_{s}$ is the hydraulic conductivity of the soil at ground surface. $f^{*}$ is the infiltration rate that used in Eq. (5). After calculating $f^{*}$ and $F^{*}\left(\sum_{i=1}^{n} f_{i}\right.$, where $\mathrm{n}$ is the no of time), these values are put in the Eq. (5) for calculating the value of time dependent suction head $h_{e}(t)$.

\section{NUMERICAL FORMULATION}

The 1-D continuity and momentum equation used in this study is a set of hyperbolic equations. These equations are nonlinear partial differential equation is not amenable to analytical solution except for very simplified cases. Different numerical methods have been used by different researchers to approximate 


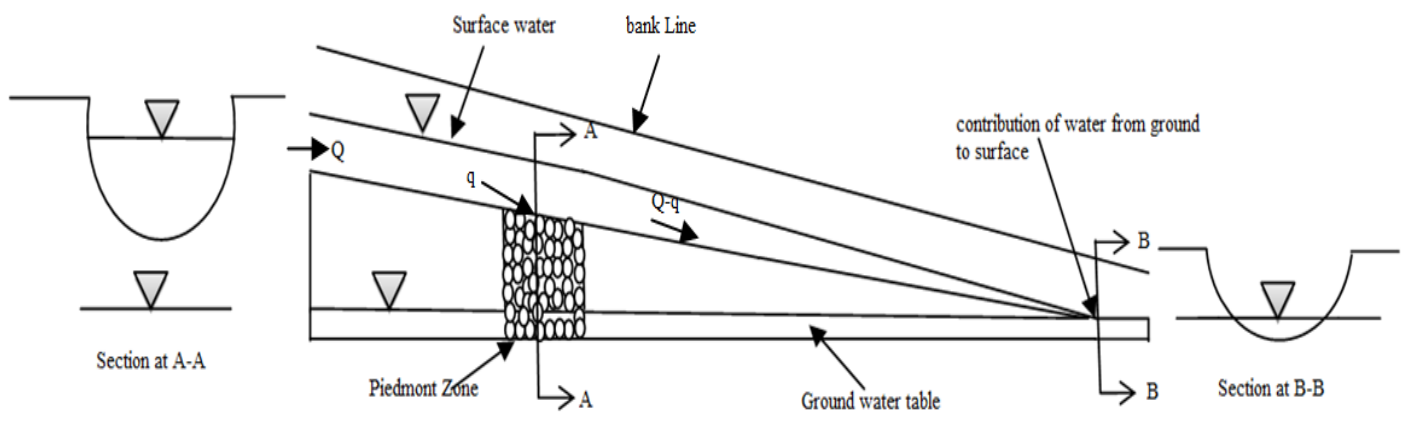

Fig. 1. Schematic representation of the physical situation.

Saint-Venant equation. Characteristic equation, Finite difference, finite element and finite volume are the numerical methods which have been used for numerical integration of SaintVenant equation. Out of all the schemes finite difference schemes are used extensively by the researchers due to its ease of application and programming and found satisfactory results in different hydrodynamic problems. Though the explicit schemes are relatively simple to set up and program, main disadvantage of explicit schemes is time step limit. But for implicit scheme one can go for much larger time step then explicit scheme. Therefore use of implicit scheme reduces the time step compare to explicit scheme. Beam and Warming (1976) developed a non-iterative implicit scheme for hyperbolic systems in conservative law form. Later various researchers e.g. Molls et al. (1995), Molls and Zhao (2000), Kassem and Chaudhry (2005) and Kalita et al. (2014) applied this scheme for solution of unsteady free surface flow problem and found satisfactory results. Beam and Warming scheme used in this study is described below (Chaudhry, 2008)

$\left[\mathbf{I}+\frac{\Delta t}{2}\left(\frac{\partial \mathbf{P}}{\partial x}+\mathbf{B}\right)^{k}\right] \Delta_{t} \mathbf{U}^{k+1}=-\Delta t\left(\frac{\partial \mathbf{E}}{\partial x}+\mathbf{S}\right)^{k}$

where $\mathbf{I}$ is the identity matrix, $\mathbf{P}$ and $\mathbf{B}$ are the Jacobians of $\mathbf{E}$ and $\mathbf{S}$ respectively and given as

$$
\begin{aligned}
& \mathbf{P}=\left(\begin{array}{cc}
0 & 1 \\
g \mathbf{D}-V^{2} & 2 V
\end{array}\right) \\
& \mathbf{B}=\left(\begin{array}{cc}
0 & 0 \\
\left(-g S_{0}-1.33 g n^{2} V|V|\right) / R^{1.33} & g n^{2}|V| / R^{1.33}
\end{array}\right),
\end{aligned}
$$

For correct signal transmission, the matrix $\mathbf{P}$ and $\mathbf{E}$ may be split as

$\mathbf{P}=\mathbf{P}^{+}+\mathbf{P}^{-}, \mathbf{E}=\mathbf{E}^{+}+\mathbf{E}^{-}$

where $\mathbf{P}^{+}=\mathbf{M D}^{+} \mathbf{M}^{-1} ; \mathbf{P}^{-}=\mathbf{M D}^{-} \mathbf{M}^{-1} ; \mathbf{E}_{x}^{+}=\mathbf{P}^{+} \mathrm{U}_{x} ; \mathbf{E}_{x}^{-}=\mathbf{P}^{-} \mathbf{U}_{x}$ $\mathbf{D}=\left(\begin{array}{cc}V+c & 0 \\ 0 & V-c\end{array}\right)$ is the diagonal matrix of eigenvalues of $\mathbf{P}$ and

$$
\mathbf{M}=\left(\begin{array}{cc}
1 /(2 c) & -1 /(2 c) \\
(V+c) /(2 c) & -(V-c) /(2 c)
\end{array}\right)
$$

Substituting the values of Eq. (11) into Eq. (9)

$$
\left[\mathbf{I}+\frac{\Delta t}{2}\left\{\frac{\partial}{\partial x}\left(\mathbf{P}^{+}+\mathbf{P}^{-}\right)+\mathbf{B}\right\}^{k}\right] \Delta_{t} \mathbf{U}^{k+1}=-\Delta t\left[\frac{\partial}{\partial x}\left(\mathbf{E}^{+}+\mathbf{E}^{-}\right)+\mathbf{S}\right]^{k}
$$

Finite Difference form of equation (13) may be written as

$$
\begin{aligned}
& {\left[\mathbf{I}+\frac{1}{2} \frac{\Delta t}{\Delta x}\left\{\left(\nabla_{x} \mathbf{P}^{+}+\Delta_{x} \mathbf{P}^{-}\right)+\frac{\Delta t}{2} \mathbf{B}_{i}\right\}^{k}\right] \Delta_{t} \mathbf{U}^{k+1}} \\
& =-\frac{\Delta t}{\Delta x}\left[\mathbf{P}_{i}^{+} \nabla_{x} \mathbf{U}+\mathbf{P}_{i}^{-} \Delta_{x} \mathbf{U}\right]^{k}-\Delta t \mathbf{S}_{i}^{k}
\end{aligned}
$$

where $\nabla_{x} \mathbf{P}^{+}=\mathbf{P}_{i}^{+}-\mathbf{P}_{i-1}^{+}$and $\Delta_{x} \mathbf{P}^{-}=\mathbf{P}_{i+1}^{-}-\mathbf{P}_{i}^{-}$.

The left-hand side of Eq. (14) constitutes the block tridiagonal system for each time step which is solved by using Thomas algorithm.

Green-Ampt equation is solved using explicit finite difference scheme. The final expression for Green-Ampt infiltration equation is given below

$$
\begin{aligned}
& F_{i}^{j+1}=F_{i}^{j}-\Delta t k_{0}\left[1+\frac{\left[h_{e}(t)_{i}^{j}+H(t)_{i}^{j}\right]\left[\theta_{s}-\theta_{o}\right]}{F_{i}^{j}}\right] \\
& h_{e}(t)_{i}^{j}=\frac{\left(F^{*}\right)_{i}^{j}\left[\left(f^{*}\right)_{i}^{j}-k_{0}\right]}{\left(\theta_{s}-\theta_{o}\right) k_{0}}-H(t)_{i}^{j}
\end{aligned}
$$

\section{VALIDATION OF THE MODEL}

The proposed model was validated using published field data of Trout Creek River (Niswonger et al., 2005). Trout Creek is a mountain front stream that drains the northwest flank of Battle Mountain near Valmy, Nevada. It is a high gradient river with very low depth of flow and having the seepage loss throughout the river. Mountain front streams may not follow same hydraulic conductivity throughout the river because of decrease of sediment size. In general hydraulic conductivity decreases downstream in mountain front stream. However, near the piedmont zone the hydraulic conductivity do not increase because of poorly sorted debris flow deposits acting like a sieve to infiltrating water. Three values of hydraulic conductivity were used for the model as per Table 1 (Niswonger et al., 2005). Parameter values used in the Green-Ampt model for calculating water infiltration through the river bed is shown in Table 2. The Saint-Venant equations expressed by Eq. (1) and 
(a)

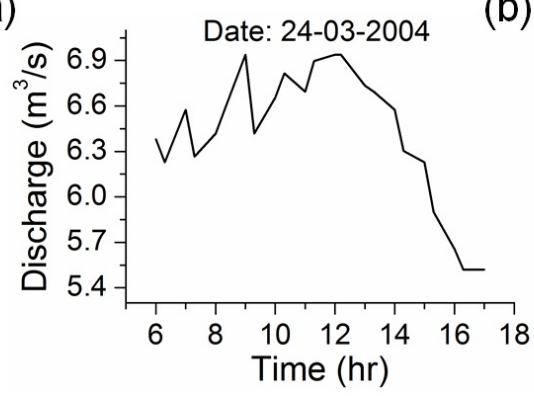

(b)

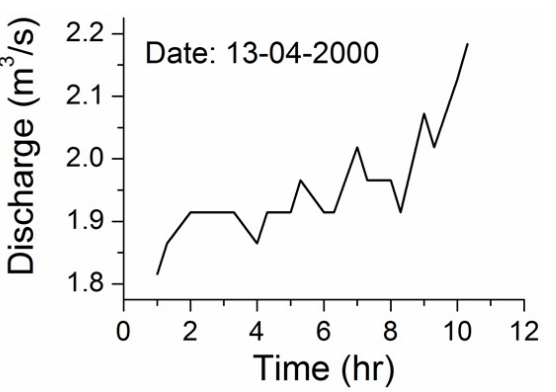

Fig. 2. Upstream boundary condition (a) for the date of $24 / 03 / 2004$, (b) for the date of $24 / 03 / 2004$.

Table 1. Variation of hydraulic conductivity with distance.

\begin{tabular}{ll}
\hline $\begin{array}{l}\text { Distance of the river } \\
\text { from upstream }\end{array}$ & Hydraulic conductivity $(\mathrm{m} / \mathrm{s})$ \\
\hline $5.88 \mathrm{~km}$ & 0.000005 \\
$3.22 \mathrm{~km}$ & 0.000007 \\
$2.1 \mathrm{~km}$ & 0.00001 \\
\hline
\end{tabular}

Table 2. Parameter used in Green-Ampt infiltration model.

\begin{tabular}{ll}
\hline Parameter & Values \\
\hline Hydraulic conductivity & Variable (as per table 1) \\
Initial water content & 0.072 \\
Saturated water content & 0.36 \\
\hline
\end{tabular}

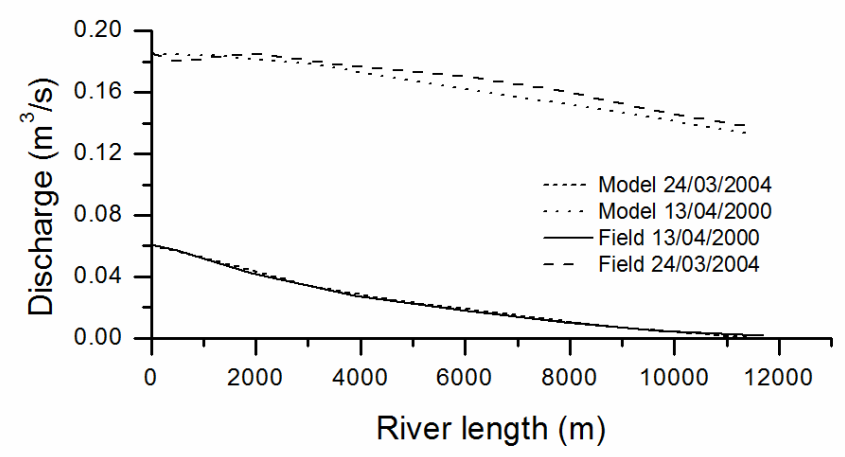

Fig. 3. Comparison of model data with field data.

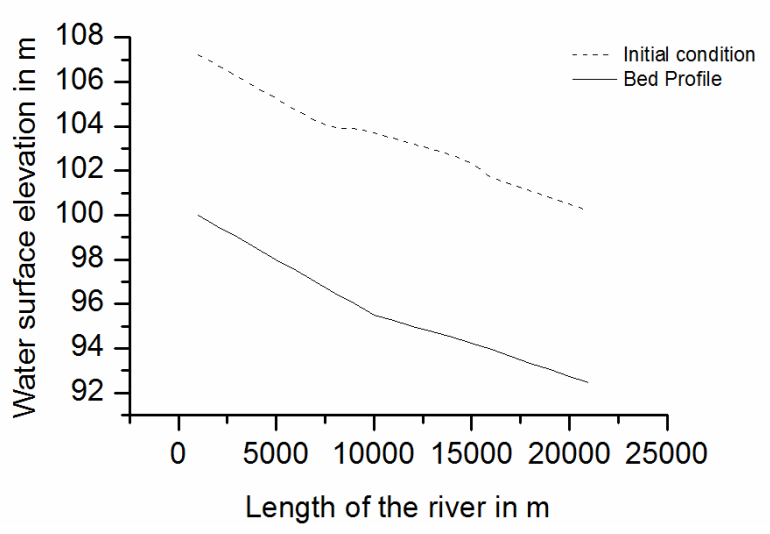

Fig. 4. Initial condition.
Eq. (2) were used to calculate the flow parameters in the river reach of length $11.2 \mathrm{~km}$. Beam and Warming finite difference scheme was used to solve the equations in the interior grid. A uniform flow of $1.83 \mathrm{~m}^{3} / \mathrm{s}$ and $6.4 \mathrm{~m}^{3} / \mathrm{s}$ is used as an initial condition for the year of 2000 and 2004 respectively. Discharge hydrograph measured above Marrigold Mine was used as the upstream boundary condition (Figure 2). Values of flow parameters at downstream boundary were calculated by the characteristic equations as described in Eq. (17) and Eq. (18). Model results were observed to be in good agreement with the observed field data (Figure 3).

\section{MODEL APPLICATION}

To assess the effect of piedmont zone on downstream hydrograph, the proposed model is applied to a hypothetical river commensurate with the size of major tributaries of Brahmaputra Basin of India where reportedly such piedmont zones exist (Goswami et al., 1996). Because of economic constraints and other difficulties of installation, sufficient numbers of gauging stations are not there in most of the tributaries of Brahmaputra Basin. Therefore, for various engineering activities like construction of flood embankment for preventing inundation, design of spurs for river bank protection and planning of dam for irrigation or hydropower, measured flow at an upstream gauging station is routed down to the location of interest by using hydrodynamic model. If piedmont zone exist between the upstream gauging station and location of interest at downstream, the estimated flow may become erroneous if existence of such high infiltration zone is not considered in the hydrodynamic model used for routing the flood and hence may lead to a faulty design. Possible effect of such piedmont zone on flow computation in such river is analysed in this section by applying the proposed model.

\section{Initial conditions}

A hypothetical river reach of $20 \mathrm{~km}$ length with three different slopes is considered. Upper reach has a length of $10 \mathrm{~km}$, middle reach has a length of $5 \mathrm{~km}$ and lower reach has a length of $5 \mathrm{~km}$. The slopes of the reaches are 1:2000, 1:3000 and 1:2500 respectively. The cross- sectional dimensions of all the three reaches are considered to be same. The width of the river is considered as $500 \mathrm{~m}$. Piedmont zone is considered to be there at $10 \mathrm{~km}$ from the upstream section. A steady gradually varied flow profile computed for the initial steady state discharge is considered as initial condition. Figure 4 represents the initial condition of the hypothetical river. 


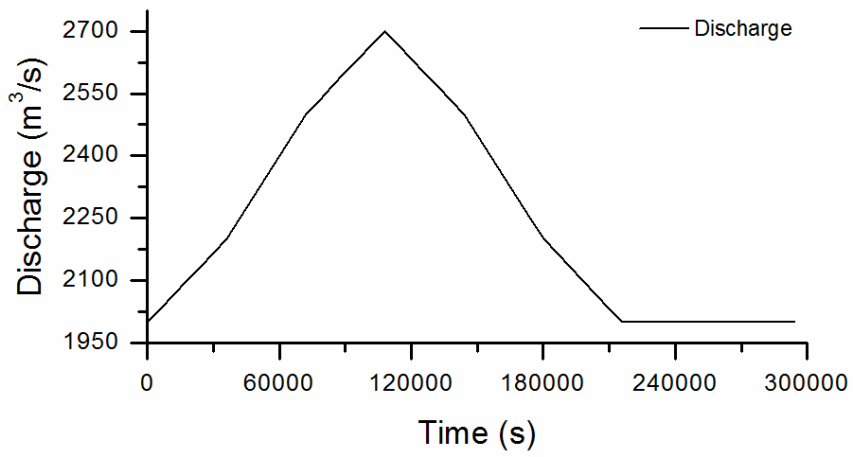

Fig. 5. Upstream boundary condition.

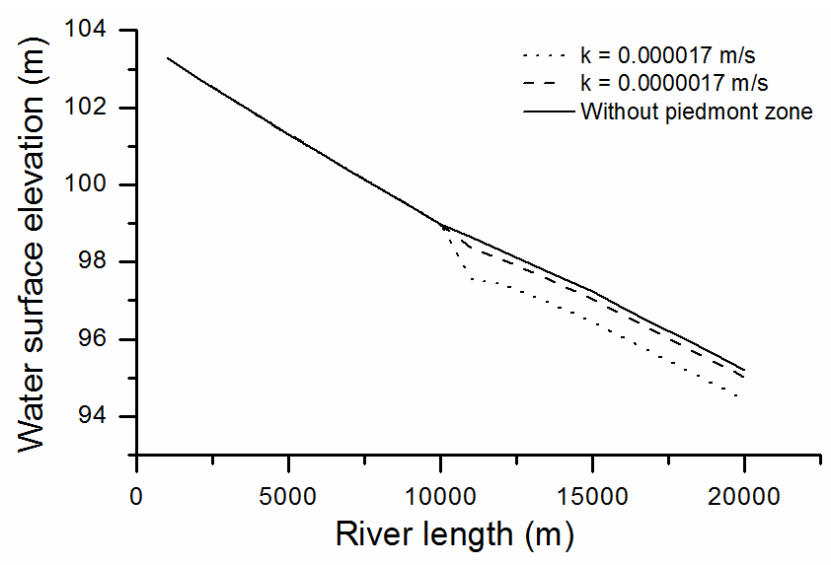

Fig. 6. Water surface elevation after $1000 \mathrm{~min}$.

\section{Boundary condition}

Numerical form of Saint-Venant equation can be solved in the interior grid points only. It is not possible to solve at the boundaries. Therefore to calculate the flow parameters at the boundaries we need two boundary conditions. One is upstream boundary condition and another is downstream boundary condition. Another boundary condition known as intermediate boundary condition is required if we consider the lateral outflow and inflow water in the main stream.

\section{Upstream boundary condition}

The discharge hydrograph as shown in Figure 5 has been taken as the upstream boundary condition.

\section{Downstream boundary condition}

To calculate the flow parameter at the downstream boundary we have used two equations i.e. positive characteristic equation, Eq. (17) and Manning's equation, Eq. (18)

$$
V_{i-1}^{j}+2 c_{i-1}^{j}=V_{i}^{j+1}+2 c_{i}^{j+1}
$$

for $\frac{d x}{d t}=V+c ; \quad V=\frac{1}{n} y^{\frac{2}{3}} S_{f}^{\frac{1}{2}}$

where $v_{i}^{j}$ is the velocity at $i^{\text {th }}$ grid in space and $j^{\text {th }}$ grid in time. $c_{i}^{j}$ is the celerity at $i^{\text {th }}$ grid in space and $j^{\text {th }}$ grid in time. Celerity $c$ is computed by using expression for rectangular channel as $c=\sqrt{g y}$. Where $g$ is the acceleration due to gravity and $y$ is the flow depth.

In case of availability of water level at any control section at downstream, downstream boundary condition can be replaced by flow depth at that control section.

\section{Intermediate boundary condition}

Once the flow reaches the piedmont zone, the flow process changes. Therefore, an intermediate boundary condition was introduced at the upstream of the piedmont zone. The intermediate boundary is solved by the positive characteristic equation and Manning's equation as discussed earlier in case of downstream boundary condition.

\section{RESULT AND DISCUSSION OF THE HYPOTHETICAL MODEL}

This section presents the influence of piedmont zone on surface profile and flow hydrograph at a downstream section. Water surface profiles, and the discharge and the depth hydrographs at $15 \mathrm{~km}$ section computed with and without piedmont zone helped assessing its effect.

\section{Water surface elevation}

Figure 6 shows the water surface profiles computed by considering recharge zone with different values of hydraulic conductivity. Comparison of this figure has revealed that the water surface elevation at the downstream of the recharge zone decreases with increase in the value of hydraulic conductivity $k$, as significant amount of water infiltrates in to the ground through the recharge zone.

\section{Discharge and depth hydrograph}

Figures $7 \mathrm{a} \& 7 \mathrm{~b}$ show the discharge and depth hydrographs respectively computed at a section $15 \mathrm{~km}$ downstream from the upstream boundary. Hydrographs computed by 1) considering piedmont zone and 2) ignoring effect of piedmont zone are plotted together for better visual comparison.

From these figures it is seen that due to presence of recharge zone in the river, the discharge and depth attenuates significantly at downstream. Reduction in peak discharge is in the order of $300 \mathrm{~m}^{3} / \mathrm{s}$, which is approximately $10 \%$ of the peak flow without considering recharge zone. Similarly depth attenuation was computed as $14 \%$. From this, it is clear that due to presence of recharge zone in a river a significant amount of water moves as subsurface flow.

Figures $8 \mathrm{a}, \mathrm{b}$, c show the sensitivity of depth, peak discharge, and flow volume vs. hydraulic conductivity respectively. The central value of hydraulic conductivity is taken as $0.0005 \mathrm{~m} / \mathrm{s}$, which is a logical value for sand-gravel mixture, which is commonly found in riverbed of such permeable river. From these figures it is observed that during the period of low discharge, for a variation of $\pm 100 \%$ in the value of hydraulic conductivity, percentage change in peak discharge and peak depth varies within a range of $\pm 0.5 \%$ and $\pm 5.0 \%$ respectively. During the high flow period, for same variation in hydraulic conductivity, percentage changes of peak discharge and peak depth range between $\pm 4.2 \%$ and $\pm 7.0 \%$, respectively, i.e. from these figure it is revealed that for high discharge river with the 
(a)

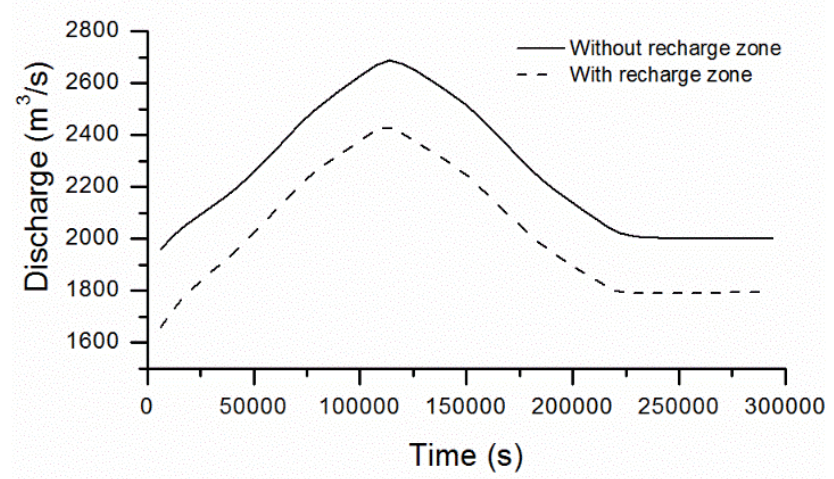

(b)

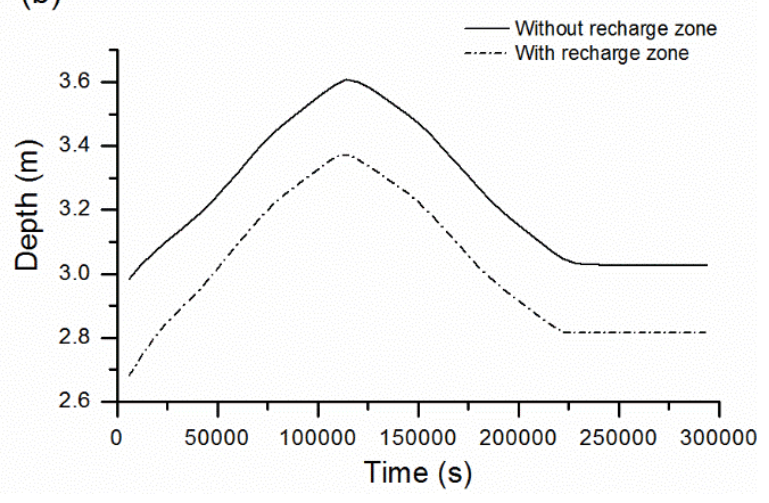

Fig. 7. Discharge and depth hydrographs with and without recharge zone. (a) Discharge hydrograph. (b) Depth hydrograph.

(a)

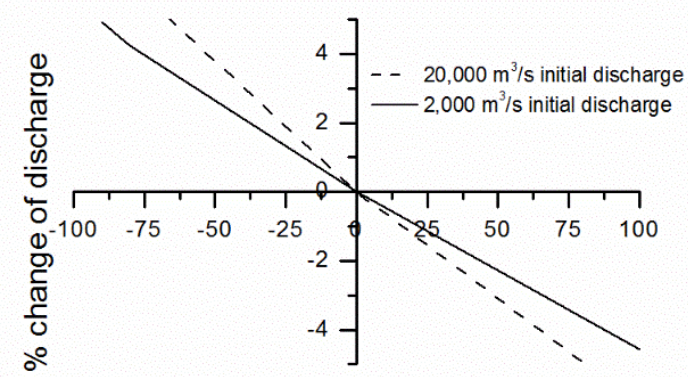

$\%$ change of hydraulic conductivity

(c)

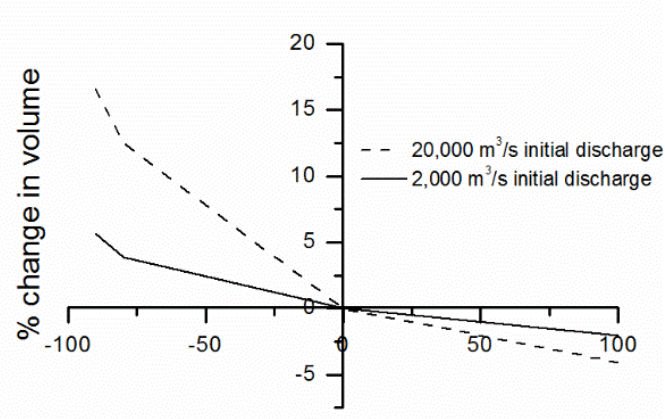

$\%$ change in hydraulic conductivity (b)

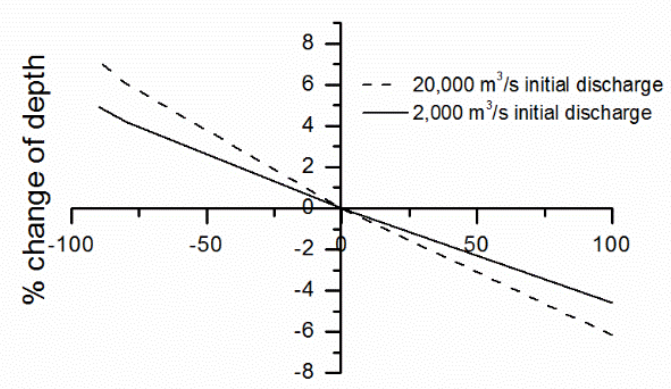

$\%$ change of hydraulic conductivity

(d)

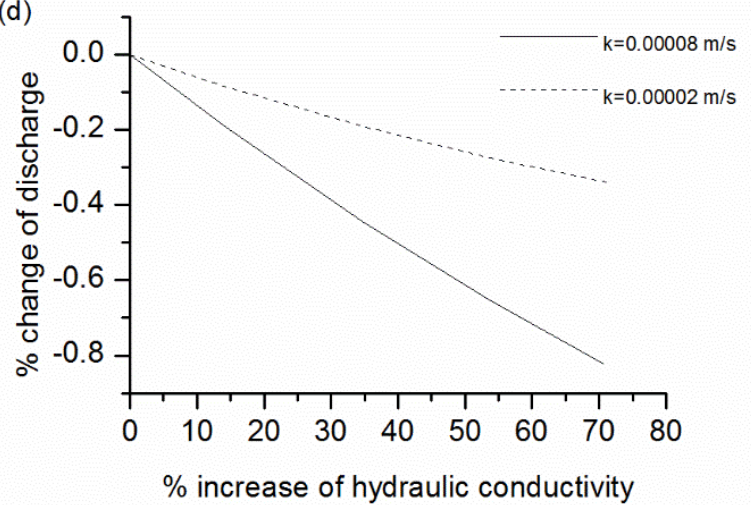

Fig. 8. (a) Sensitivity of peak discharge $v s$. permeability, (b) sensitivity of peak depth $v s$. permeability, (c) sensitivity of volume vs. permeability, and (d) discharge vs. hydraulic depth plots

variation of hydraulic conductivity, percentage change in peak discharge and depth are more than low discharge river. From Figure 8c, it is observed that effect of hydraulic conductivity is significant on volume change. For low discharge of $2000 \mathrm{~m}^{3} / \mathrm{s}$, with increase in the value of hydraulic conductivity from an initial impermeable status, the channel flow volume decreases at a much higher rate and then decreases gradually with a uniform rate beyond $k=0.0002 \mathrm{~m} / \mathrm{s}$. For higher discharge of $20000 \mathrm{~m}^{3} / \mathrm{s}$, decrease in channel flow volume is also high. Up to a value of $k=0.0005 \mathrm{~m} / \mathrm{s}$, the rate of percentage change in flow volume remain high and then it drop gradually to a uniform low rate. As the model results for different discharges were derived in a $500 \mathrm{~m}$ wide hypothetical channel, an analysis to examine effect of hydraulic depth on flow parameters was also carried out. Figure $8 \mathrm{~d}$ presents the effect of hydraulic depth on infiltration characteristic. Analysis has been done for two values of hydraulic conductivity, where hydraulic depth changes up to $80 \%$ and found that for $k=0.001 \mathrm{~m} / \mathrm{s}$, the maximum change of discharge because of infiltration through the piedmont zone is $0.33 \%$. Similarly for $k=0.005 \mathrm{~m} / \mathrm{s}$ the change of discharge is $0.82 \%$. Figure $8 \mathrm{~d}$ revealed that the effect of hydraulic depth, on in discharge is less significant as compared to the effect of hydraulic conductivity, i.e. with other parameters remain constant hydraulic depth does not have significant effect on infiltration through piedmont zone. 


\section{CONCLUSIONS}

A mathematical model for computing flood propagation in a river having piedmont zone was proposed. The model was validated with the field data of Trout Creek River and was found to be in good agreement with our model calculations. The model was then applied to a hypothetical river commensurate with the size and characteristic of major tributaries of Brahmaputra Basin of India with and without the presence of piedmont zone in the model. The result showed a $10 \%$ and $14 \%$ difference in the discharge and depth hydrograph in presence and absence of piedmont zone respectively. The results obtained from the sensitivity analysis of peak depth, peak discharge, and flow volume versus hydraulic conductivity showed a small effect of these parameters on hydraulic conductivity but cannot be ignored since these values can considerably influence the design of downstream hydraulic structures. Our results indicated that the presence of piedmont zone in river bed and the effect of the permeability characteristics of the zone can significantly influence the unsteady flow in a river and are critical parameters to accurately determine the downstream river flow scenario with potential impact on water resources planning and flood management.

Governing equation used in the model are Saint-Venant equation and Green-Ampt infiltrating equation. The assumptions made in the governing equations are also the limitation for the model. Again the developed model is one dimensional unsteady flow model considering the effect of piedmont zone in the river bed. For large river one dimensional model is not useful to predict the flow scenario. In that case 2-D and 3-D models perform better to predict the flow characteristics. Again the model calculated the amount of water that is infiltrated through the piedmont zone. But it is not described the movement of infiltrated water. Therefore in future model has the scope of further development to a 2-D or 3-D model considering the groundwater movement of the infiltrating water.

\section{REFERENCES}

Akanbi, A.A., Katopodes, N.D., 1990. Model for flood propagation on initially dry land. J. Hydraul. Eng., 114, 689-706.

Bateman, A., Medina, V., Velasco, D., 2010. Soil infiltration effect in flat areas floods simulations. In: XVIII International Conference on Water Resources, CIMNE, Barcelona.

Beam, R.M., Warming, R.F., 1976. An implicit finite difference algorithm for hyperbolic systems in conservation law form. J. Comput. Phys., 22, 87-110.

Beven, K., 1984. Infiltration into a class of vertically nonuniform soils. Hydrolog. Sci. J., 29, 425-434.

Chaudhry, M.H., 2008. Open channel flow. 2nd edition. Prentice-Hall Inc, Englewood Cliffs.

Chou, S.T., 1978. Infiltration during an unsteady rain. Water Resour. Res., 14, 3, 461-466.

Dagan, G., Bresler, E., 1983. Unsaturated flow in a spatially variable. 1. Derivation of models of infiltration and redistribution. Water Resour. Res., 19, 2, 413-420.

Fang, H., Chen, M., Chen, Q., 2008. One-dimensional numerical simulation of non-uniform sediment transport under unsteady flows. J. Sediment. Res., 23, 315-328.

Fennema, R.J., Chaudhry, M.H., 1986. Explicit numerical schemes for unsteady free-surface flow with shocks. Water Resour. Res., 22, 13, 1923-1930.

Fiedler, F.R., Ramirez, J.A., 2000. A numerical method for simulating discontinuous shallow flow over an infiltrating surface. Int. J. Numer. Meth. Fluids, 32, 219-240.
Freyberg, D.L., Reeder, J.W., Franzini, J.B., Remson, I., 1980. Application of the Green-Ampt model to infiltration under time-dependent surface water depth. Water Resour. Res., 16, $3,517-528$.

Goswami, D.C., Goswami, I.D., Duarah, B.P., Deka, P.P., 1996. Geomorphological mapping of assam using satellite remote sensing techniques. Indian J. Geomorph., 1, 2, 225235.

Govindaraju, R.S., Kavvas, M.V., Jones, S.E., Rolston, D.E., 1996. Green-Ampt model for analysing one-dimensional convective transport in unsaturated soils. J. Hydrol., 178, 337-350.

Kacimov, A.R., Al-Ismaily, S., Al-Maktoumi, A., 2010. GreenAmpt one-dimensional infiltration from a ponded surface into heterogeneous soil. J. Irrig. Drain Eng., 136, 1, 68-72.

Kalita, H.M., Sarma, A.K., 2012. Efficiency and performances of finite difference schemes in the solution of saint Venant's equation. Int. J. Civ. Struct. Eng. Res., 2, 3, 950-958.

Kalita, H.M., Sarma, A.K., Bhattacharjya, R.K., 2014. Evaluation of optimal river training work using GA based linked simulation-optimization approach. Water Resour. Manag., 28, 2077-2092.

Kassem, A.A., Chaudhry, M.H., 1998. Comparison of coupled and semi coupled numerical models for alluvial channels. J. Hydraul. Eng., 124, 8, 794-802.

Kassem, A.A., Chaudhry, M.H., 2005. Effect of bed armoring on bed topography of channel bends. J. Hydrol. Eng., 131, 12, 1136-1140.

Keskin, M.E., Agiralioglu, N., 1997. A simplified dynamic model for flood routing in rectangular channels. J. Hydrol., 202, 302-314.

Kong, J., Xin, P., Song, Z.Y., Li, L., 2010. A new model for coupling surface and subsurface water flows: with an application to a lagoon. J. Hydrol., 390, 116-120.

Liang, D., Falconer, R.A., Lin, B., 2007. Coupling surface and subsurface flows in a depth averaged flood wave model. J. Hydrol., 337, 147-158.

Lui, J., Zhang, J., Feng, J., 2008. Green-Ampt model for layered soils with nonuniform initial water content under unsteady infiltration. Soil Sci. Soc. Am. J., 72, 4, 1041-1047.

Ma, Y., Feng, S., Su, D., Gao, G., Huo, Z., 2010. Modeling water infiltration in a large layered soil column with a modified Green-Ampt model and Hydrus- 1D. Comput. Electron. Agr., 71S, S40-S47.

Mein, R.G., Larson, C.L., 1973. Modeling infiltration during a steady rain. Water Resour. Res., 9, 2, 384-394.

Mohammad, R.H., Mohammad, J.A., Parviz, M., 2007. A differential quadrature analysis of unsteady open channel flow. Journal of Appl. Math. Model., 31, 8, 1594-1608.

Molls, T., Zhao, G., 2000. Depth-averaged simulation of supercritical flow in channel with wavy sidewall. J. Hydraul. Eng. ASCE, 126, 6, 437-445.

Molls, T., Chaudhry, M.H., Khan, K.W., 1995. Numerical simulation of two-dimensional flow near a spur-dike. Adv. Water Resour., 18, 4, 221-236.

Mousseau, V.A., Knoll, D.A., Reisner, J.M., 2002. An Implicit Nonlinearly Consistent Method for the Two-Dimensional Shallow-Water Equation with Coriolis Force. American Meteorological Society, 130, 2611-2625.

Niswonger, R.G., Prudic, D.E., Pohll, G., Constantz, J., 2005. Incorporate seepage losses into the unsteady stream flow equations for simulation intermittent flow along mountain front streams. Water Resour. Res., 41, W06006. 
Patowary, S., Sarma, A.K., 2013. Hydrodynamic flood routing considering piedmont zone. Int. J. Civ. Struct. Eng. Res., 3, 3, 464-474.

Ramesh, R., Datta, B., Bhallamudi, M., Narayana, A., 2000. Optimal estimation of roughness in open-channel flows. J. Hydraul. Eng. ASCE, 126, 4, 299-303.

Reeder, J.W, Freyberg, D.L., Franzini, J.B., Remson, 1980. I. Infiltration under rapidly varying surface water depths. Water Resources Research, 16, 1, 97-104.

Selker, J.S., Duan, J., Parlange, J.Y., 1999. Green and Ampt infiltration into soils of variable pore size with depth. Water Resour. Res., 35, 5, 1685-1688.

Strelkoff, T., 1970. Numerical solution of Saint-Venant equations. J. Hydraul. Eng., 96, 223-252.
Suils, M., Meyerhoff, S.B., Paniconi, C., Maxwell, R.M., Putti, M., Kollet, S.J., 2010. A comparison of two physic-based numerical models for simulating surface water-groundwater interactions. Adv. Water Resour., 33, 456-647.

Voller, V.R., 2011. On a fractional derivative form of the Green-Ampt infiltration model. Adv. Water Resour., 34, 257-262.

Zhang, M.L., Shen, Y.M., 2007. Study and application of steady flow and unsteady flow mathematical model for channel networks. Journal of Hydrodynamics, 19, 572-578.

Received 19 October 2015 Accepted 26 July 2016 